\title{
Avaliando a sustentabilidade alcançada por meio de entregas noturnas: o caso da distribuição de combustíveis na cidade do Rio de Janeiro
}

\author{
Diego Marques da Silva ${ }^{1}$, Renata Albergaria de Mello Bandeira ${ }^{2}$, Vania Barcelos Gouvêa Campos ${ }^{3}$ \\ ${ }^{1}$ Instituto Militar de Engenharia, dimarques19@gmail.com \\ 2Instituto Militar de Engenharia, re.albergaria@gmail.com \\ 3Instituto Militar de Engenharia, vania@ime.eb.br
}

\section{Recebido:}

27 de julho de 2017

Aceito para publicação:

28 de março de 2018

Publicado:

XX de XX de 2018

Editor de área:

Marcio D'Agosto

\section{Palavras-chaves:}

Logística,

Transporte Urbano de Carga,

Entrega Noturna.

Keywords:

Logistics,

Urban Cargo Transport,

Night Delivery.

DOI:10.14295/transportes.v25i2.1437

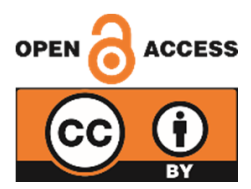

\begin{abstract}
RESUMO
Este trabalho tem como objetivo analisar o impacto que a implantação de iniciativas para aumentar o desempenho do transporte de carga pode gerar na distribuição de combustiveis em áreas urbanas, em relação à sustentabilidade ambiental e econômica, bem como à eficiência da operação. Desta forma, o artigo propõe uma metodologia a ser das iniciativas com maior potencial, em termos de custo e eficiência, para contribuir para o processo de distribuição de combustíveis em áreas urbanas, bem como para a avaliação do impacto de sua implantação, em termos econômicos e ambientais. O resultado apontou a entrega noturna como a prática com maior potencial de ganhos para o setor, de modo que a metodologia proposta é aplicada para avaliar os resultados de um experimento de entregas noturnas de combustíveis na zona Sul da cidade do Rio de Janeiro, em uma das maiores distribuidoras do Brasil. Os resultados do período de teste de entregas noturnas foram comparados em relação às entregas diurnas, prática padrão da empresa. Foram observados diversos resultados positivos durante o processo de entrega noturna, tais como:, $9 \%$ de redução no consumo de combustível; $66 \%$ de aumento na velocidade média operacional dos caminhões; redução média de $31 \%$ no tempo de viagem, possibilitando o aumento do número de viagens diárias por veículo com a utilização de um mesmo motorista; além da redução média de $13 \%$ na emissão de poluentes atmosféricos e gases de efeito estufa no meio ambiente..
\end{abstract}

\begin{abstract}
This paper aims to analyze impact that initiatives for improving freight system performance can generate in fuel distribution in urban areas. Therefore, we propose a comprehensive methodology to identify innitiatives with the most potential in terms of cost and efficiency for the fuel distribution process in urban area, and then to assess its impacts, in terms of environmental and economic sustainability. Results indicated offhours deliveries as the practice with the higher potential, and thus an application of the proposed methodology is presented to assess results of an experiment of off-hours deliveries held in a fuel distribution process in Rio de Janeiro city in comparison to daytime deliveries, which is the company's standard practice. Several positive results were observed during off-hour deliveries, such as: $9 \%$ reduction in fuel consumption; $66 \%$ increase in average operational speed; a $31 \%$ reduction in travel time; possibility of carrying out two trips with the same vehicle per day; reducing expenses with drivers when there is an increase in daily truck deliveries; as well as an average $13 \%$ reduction in emission of air pollutants and Greenhouse gases.
\end{abstract}

\section{INTRODUÇÃO}

Segundo estimativas das Nações Unidas, dois terços da população mundial, até 2030, viverá em áreas urbanas (ONU, 2016). A concentração da população brasileira em áreas urbanas também 
obteve um crescimento considerável nos últimos anos, com destaque para o estado do Rio de Janeiro, cujo percentual de habitantes em áreas urbanas subiu de 79\%, na década de 60, para 96,7\% em 2010 (IBGE, 2010). Este aumento da concentração de habitantes gera maior demanda por serviços de transporte para a distribuição de bens, implicando em impactos sociais, ambientais e econômicos, sobretudo em relação à intensificação dos congestionamentos de viagens, da poluição sonora, à emissão de poluentes atmosféricos e gases de efeito estufa, além de promover o aumento dos custos e diminuir a segurança da população, em função do aumento do número de acidentes (Mckinnon et al., 2010; Oliveira et al., 2015).

Consequentemente, as autoridades locais tentam minimizar tais impactos por meio de incentivos e restrições ao Transporte Urbano de Carga (TUC), como a restrição para circulação de caminhões em determinadas vias, horários de circulação dos veículos de carga nos perímetros urbanos e também nos locais de carga e descarga dos produtos (Arvindsson, 2013). Entretanto, tais restrições dificultam a distribuição de suprimentos nas metrópoles por parte do operador. No segmento de distribuição de combustíveis, há ainda alguns agravantes, por se tratar de transporte de produtos perigosos classe 3 - Líquidos Inflamáveis, segundo a classificação da resolução 420/2004 da Agência Nacional de Transportes Terrestres (ANTT, 2004). Essa particularidade acarreta proibições específicas de acesso a algumas vias, proibições de horário de circulação, além da legislação particular que atende a esse segmento. Aliado a essa particularidade do produto, também há a capilaridade dos clientes e suas exigências para entregas em janelas de tempo específicas, que dificultam o planejamento das entregas neste setor. Deste modo, o presente estudo é concentrado na aplicação de práticas de logística urbana no setor de distribuição de combustíveis, devido a sua complexidade de entrega e periculosidade no transporte, considerando a perspectiva do operador.

Neste contexto, o presente artigo tem como objetivo analisar o processo de distribuição de combustíveis em áreas urbanas, com intuito de identificar as principais medidas que contribuem para aumentar a eficiência do processo. Para tanto, tomou-se como base um conjunto de iniciativas, consolidadas por Holguín-Veras (2015), cujo objetivo era trazer melhorias para a eficiência do transporte de carga em regiões metropolitanas. Assim, considerando toda a particularidade da distribuição de combustíveis, procurou-se identificar, por meio de entrevistas com especialistas, as práticas com maior potencial, em termos de eficiência e custo, para este segmento. Como resultado, os especialistas apontaram a prática de entregas noturnas como a de maior potencial para a distribuição de combustíveis. Deste modo, realizou-se uma análise da sustentabilidade econômica e ambiental, bem como o nível de serviço oferecido, da prática de distribuição noturna, por meio de um estudo de caso de uma empresa distribuidora de combustíveis, que atua na cidade do Rio de Janeiro, Brasil.

Para o estudo de caso, foi escolhida a cidade do Rio de Janeiro devido à alta densidade demográfica e também por ter recebido as Olimpíadas de 2016. Durante a realização deste evento, rotina de entrega dos veículos de carga foi alterada por diversas restrições, possibilitando assim a comparação do desempenho das entregas em períodos diurno e noturno. 0 estudo foca nas entregas dos distribuidores para os clientes. A amostra adotada foi a região da zona sul carioca, onde 12 clientes recebem combustíveis de uma grande distribuidora, por meio da modalidade Cost, Insurance and Freight (CIF), onde o distribuidor tem a responsabilidade sobre o frete de entrega. Destaca-se que a distribuidora estudada não possui caminhões próprios, realizando contratos de entrega com as transportadoras desse segmento. Atualmente, são contabilizados 
74 veículos compartimentados, capazes de atender os clientes localizados na região metropolitana do Rio de Janeiro com os produtos diferentes (gasolina, diesel e álcool), expedidos a partir do terminal localizado em Duque de Caxias, RJ. Na zona sul da cidade, alvo específico deste estudo, circula, aproximadamente, $10 \%$ dessa frota.

A partir desta introdução, este trabalho se divide em quatro seções. A seção 2 apresenta o método utilizado para a escolha da boa prática de transporte urbano de carga com maior potencial para o setor de distribuição de combustíveis. Na seção 3, apresenta-se a metodologia de pesquisa, descrevendo as operações avaliadas neste estudo, a técnica de coleta de dados adotada e os métodos para a avaliação econômica, ambiental e da eficiência da operação. A seção 4 discorre os resultados obtidos e suas respectivas análises. Por fim, na seção 5, encontram-se as conclusões obtidas no presente estudo.

\section{IDENTIFICAÇÃO E ANÁLISE DE INICIATIVAS PARA O TRANSPORTE DE CARGA URBANA}

Diversos estudos vêm sendo realizados pela comunidade acadêmica, com o objetivo de encontrar soluções para o segmento de transporte urbano de cargas e reduzir seus impactos negativos. Em 2013, foi realizada por Oliveira (2013) uma revisão sistemática envolvendo as publicações que abordavam a logística urbana no Brasil de 2001 até o ano de 2012, sendo utilizado o Google Scholar como base de dados para a pesquisa. 0 levantamento apontou que, em um total de 4 teses, 15 dissertações e 42 artigos, 56\% tem caráter conceitual, 25\% tem aplicação de conceitos de logística urbana, 11\% apresentam algum tipo de modelagem, enquanto 6\% foram estudos de caso e em 2\% foram realizados diagnósticos (OLIVEIRA, 2013). Estas estatísticas revelam um grande potencial para o desenvolvimento de trabalhos em busca de alternativas para a melhoria da logística urbana.

Diante de diversas pesquisas a respeito de melhorias para o TUC, destacam-se iniciativas como o VREF Center of Excellence for Sustainable Urban Freight Systems e o Best Urban Freight Solutions (BESTUFS), uma rede norte-americana e outra europeia que têm o objetivo de identificar, descrever e divulgar melhores práticas e critérios de sucesso em relação às Soluções Logísticas para as Cidades. No Brasil, Carvalho (2016) aponta uma série de iniciativas, a ser aplicada em cidades brasileiras com população superior a quinhentos mil habitantes, para melhora a eficiência do TUC nos próximos anos. Contudo, é importante uma análise destas iniciativas com o intuito de incentivar aquelas que podem trazer benefícios para todos os envolvidos no TUC.

Neste contexto, o presente artigo baseou-se em um estudo desenvolvido pelo VREF, que propôs a consolidação de 54 iniciativas para o aperfeiçoamento do transporte de carga, trazendo em seu cerne aspectos sustentáveis, elencadas em oito grupos: Gerenciamento de Infraestrutura; Gestão de áreas para carga, descarga e estacionamento; Estratégias relativas ao veículo; Gestão de viagens; Preços, incentivos e tributação; Gerenciamento Logístico; Gestão da circulação dos veículos de carga; e Engajamento das partes interessadas (Holguín-Veras, 2015). Deste total, 25 iniciativas têm como foco o TUC, que fazem parte do que o autor denomina última milha (last mile), definidas pela possibilidade de intervenção direta dos municípios, sem a dependência de outras esferas governamentais. A Tabela 1 apresenta as 25 práticas consolidadas pelo Holguín-Veras (2015) e suas definições.

Com base neste conjunto de iniciativas, consolidadas por Holguín-Veras (2015), o presente estudo buscou identificar aquelas com maior potencial, em termos de custo e eficiência, para o 
processo de distribuição de combustíveis em áreas urbanas. Desta forma, foi realizada uma análise preliminar com o objetivo de identificar quais destas 25 iniciativas de fato se aplicam à distribuição de combustíveis em áreas urbanas, segundo a realidade atual do setor no Brasil. Esta análise resultou na eliminação de quatro práticas, segundo os motivos apresentados na Tabela 2.

Tabela 1: Consolidação das práticas de última milha para o transporte urbano de cargas

\begin{tabular}{|c|c|c|}
\hline Grupo & Prática & Definição \\
\hline $\begin{array}{l}\text { Gerenciamento de } \\
\text { Infraestrutura }\end{array}$ & $\begin{array}{l}\text { Clusters de frete (aldeias de } \\
\text { frete) }\end{array}$ & $\begin{array}{l}\text { Trata-se da concentração de usuários de frete como centros de distribuição, fabricantes, } \\
\text { terminais de caminhões e instalações entre modos de transporte em um único local, para } \\
\text { fornecer eficiência e economias de escala. É uma abordagem comum de uso do solo que } \\
\text { consolida um único tipo de atividade em uma área, para reduzir os impactos negativos } \\
\text { dessa atividade em outras áreas. }\end{array}$ \\
\hline $\begin{array}{l}\text { Gestão de Áreas de } \\
\text { Carga e Descarga e } \\
\text { Estacionamento }\end{array}$ & $\begin{array}{l}\text { Edifícios para carga, descarga e } \\
\text { estacionamento }\end{array}$ & $\begin{array}{l}\text { Modelo de instalações de estacionamento e carregamento fora das principais ruas das } \\
\text { grandes metrópoles. Toda a movimentação da carga (estacionamento, carga e descarga) } \\
\text { é realizada em edifícios específicos para esta atividade. }\end{array}$ \\
\hline $\begin{array}{l}\text { Estratégias relativas } \\
\text { ao veículo }\end{array}$ & Regulamento antirruído & Regulamentos e iniciativas de entrega de baixo ruído para diminuir a poluição sonora. \\
\hline \multirow[b]{2}{*}{ Gestão de viagens } & $\begin{array}{l}\text { Restrições por tamanho do } \\
\text { veículo e de peso }\end{array}$ & $\begin{array}{l}\text { Restrições para evitar que veículos de determinado peso, tamanho (comprimento ou } \\
\text { largura), ou número de eixos usem uma determinada estrada ou área, visando reduzir } \\
\text { congestionamento e acidentes de trânsito s. }\end{array}$ \\
\hline & $\begin{array}{l}\text { Rotas alternativas para } \\
\text { caminhões }\end{array}$ & $\begin{array}{l}\text { São utilizadas para impedir que veículos de carga utilizem rotas inadequadas ou sensí- } \\
\text { veis, viando reduzir a quantidade de caminhões nestas vias. No Brasil, são exemplos } \\
\text { dessa prática a construção do rodoanel em São Paulo e do Arco metropolitano no Rio de } \\
\text { Janeiro. }\end{array}$ \\
\hline \multirow{5}{*}{$\begin{array}{l}\text { Preços, Incentivos e } \\
\text { Tributação }\end{array}$} & Pedágio & $\begin{array}{l}\text { Uma ferramenta de gerenciamento de demanda em áreas urbanas para reduzir o trá- } \\
\text { fego, promover um melhor uso da capacidade de transporte e reduzir os impactos am- } \\
\text { bientais. As receitas de preços são frequentemente usadas para financiar os custos de } \\
\text { construção e manutenção da infraestrutura urbana. }\end{array}$ \\
\hline & $\begin{array}{l}\text { Taxa de estacionamento para } \\
\text { carga e descarga }\end{array}$ & $\begin{array}{l}\text { Taxa cobrada para o uso do espaço de estacionamento na travessia, alguns com base em } \\
\text { taxas fixas, enquanto outros envolvem esquemas de preços variáveis ou diferenciados. }\end{array}$ \\
\hline & Programas de certificação & Iniciativas implementadas para incentivar e recompensar práticas sustentáveis em toda \\
\hline & Programas de reconhecimento & gramas de premiação. \\
\hline & Tributação & $\begin{array}{l}\text { Iniciativas utilizadas para aumentar as receitas do setor público por meio de taxas, im- } \\
\text { postos ou contribuições, que, por muitas vezes, promovem mudanças no comporta- } \\
\text { mento financeiro da população, por gerar despesas aos seus habitantes. }\end{array}$ \\
\hline \multirow{5}{*}{$\begin{array}{l}\text { Gerenciamento } \\
\text { Logístico }\end{array}$} & $\begin{array}{l}\text { Sistemas de Informação em } \\
\text { Tempo Real }\end{array}$ & $\begin{array}{l}\text { São um conjunto de tecnologias e estratégias que podem ajudar a monitorar e gerenciar } \\
\text { o tráfego, com base em informações de tráfego em tempo real. }\end{array}$ \\
\hline & $\begin{array}{l}\text { Sistemas de Deteç̧ão Vertical } \\
\text { Altura }\end{array}$ & $\begin{array}{l}\text { Detectam caminhões de sobre-altura que se deslocam em direção a estruturas rodoviá- } \\
\text { rias, alertando o motorista do caminhão para evitar colisões com a estrutura. }\end{array}$ \\
\hline & Roteamento Dinâmico & $\begin{array}{l}\text { São utilizados pelas autoridades públicas para aumentar a segurança e prevenir viola- } \\
\text { ções da regulação do acesso. O setor privado usa o roteamento no veículo como parte } \\
\text { de um sistema de suporte à decisão para aumentar a eficiência do gerenciamento de } \\
\text { frotas. }\end{array}$ \\
\hline & $\begin{array}{l}\text { Agendamento para Entregas } \\
\text { nos Grandes Polos geradores } \\
\text { de Viagens }\end{array}$ & $\begin{array}{l}\text { Projetado para ser usado em grandes geradores de viagens, o horário de entregas/pick- } \\
\text { ups permite que os motoristas reservem seu espaço antes de chegar ao local. }\end{array}$ \\
\hline & $\begin{array}{l}\text { Redução da Poluição causada } \\
\text { pela Marcha lenta dos Cami- } \\
\text { nhões }\end{array}$ & $\begin{array}{l}\text { Programas para reduzir a poluição causada por motores de marcha lenta. As tecnologias } \\
\text { anti-marcha lenta mais populares são aquecedores de refrigerante a combustível, uni- } \\
\text { dades de energia auxiliares e eletrificação de parada de caminhão. }\end{array}$ \\
\hline \multirow{4}{*}{$\begin{array}{l}\text { Gestão da } \\
\text { Circulação dos } \\
\text { Veículos de Carga }\end{array}$} & $\begin{array}{l}\text { Programa de Entrega fora do } \\
\text { Horário Comercial (das 19h às } \\
06 \mathrm{~h} \text { ) }\end{array}$ & $\begin{array}{l}\text { Programas que produzem um deslocamento das entregas das horas regulares (das } 6 \mathrm{~h} \text { às } \\
7 \mathrm{~h} \text { ) para as horas noturnas (7h às } 6 \mathrm{~h} \text { ). }\end{array}$ \\
\hline & $\begin{array}{l}\text { Programa de Agendamento de } \\
\text { horários para Entregas }\end{array}$ & $\begin{array}{l}\text { Programas para diminuir a demanda do caminhão durante os períodos de pico, distribu- } \\
\text { indo as horas de recebimento ao longo do dia. }\end{array}$ \\
\hline & $\begin{array}{l}\text { Programa de Mudança dos } \\
\text { Modo de Transporte }\end{array}$ & $\begin{array}{l}\text { Uma mudança dos fluxos de carga da estrada para o transporte intermodal, utilizando } \\
\text { uma combinação de transporte rodoviário e marítimo, vias navegáveis interiores, trens } \\
\text { ou triciclos. }\end{array}$ \\
\hline & $\begin{array}{l}\text { Mudança na localização dos } \\
\text { Grandes geradores de viagem }\end{array}$ & $\begin{array}{l}\text { Tem como objetivo mover grandes geradores de viagem para locais adequados bus- } \\
\text { cando mudar o padrão de geração de frete e otimizar o funcionamento geral do sistema } \\
\text { de frete urbano. }\end{array}$ \\
\hline
\end{tabular}


Tabela 1: Consolidação das práticas de última milha para o transporte urbano de cargas (continuação)

\begin{tabular}{|c|c|c|}
\hline Grupo & Prática & Definição \\
\hline \multirow{6}{*}{$\begin{array}{l}\text { Engajamento das } \\
\text { Partes Interessadas }\end{array}$} & $\begin{array}{l}\text { Criar um Comitê Consultivo de } \\
\text { carga (FAC) }\end{array}$ & $\begin{array}{l}\text { FAC é composto por um grupo de diferentes partes interessadas de frete e serve como } \\
\text { um fórum no qual são discutidas novas soluções para problemas de frete urbano. }\end{array}$ \\
\hline & Educar Funcionários Chave & $\begin{array}{l}\text { O objetivo principal desta iniciativa é criar uma compreensão entre os funcionários chave } \\
\text { sobre a importância do frete para as áreas metropolitanas e seu potencial papel no apri- } \\
\text { moramento do desempenho do sistema. }\end{array}$ \\
\hline & $\begin{array}{l}\text { Criar um Comitê Consultivo } \\
\text { Técnico (TAC) }\end{array}$ & $\begin{array}{l}\text { É um fórum no qual o pessoal do setor público nas várias agências com jurisdição em } \\
\text { assuntos que afetam a atividade de frete se reúne para discutir a política de frete. }\end{array}$ \\
\hline & $\begin{array}{l}\text { Criar uma Parceria Público-Pri- } \\
\text { vado para Melhorar a Quali- } \\
\text { dade na Entrega de Carga } \\
\text { (FQP) }\end{array}$ & $\begin{array}{l}\text { Trata-se de uma parceria voluntária entre grupos do setor privado e público para pro- } \\
\text { mover a implementação de práticas que melhorem os impactos negativos da atividade } \\
\text { de frete. }\end{array}$ \\
\hline & $\begin{array}{l}\text { Iniciativas mitigadoras para os } \\
\text { impactos negativos que os } \\
\text { operadores geram ao Meio } \\
\text { Ambiente. }\end{array}$ & $\begin{array}{l}\text { Fomentar um Programa de Divulgação de Melhores Práticas lideradas pela indústria é } \\
\text { uma iniciativa que fornece uma base sólida para o envolvimento do setor privado na } \\
\text { sensibilização e ensinando-lhes a conduzir suas atividades de forma a mitigar os impac- } \\
\text { tos negativos produzidos. }\end{array}$ \\
\hline & $\begin{array}{l}\text { Designar uma pessoa chave } \\
\text { para as questões de trans- } \\
\text { porte. }\end{array}$ & $\begin{array}{l}\text { Esta medida facilita os esforços de divulgação porque, com o tempo, esse indivíduo se } \\
\text { torna o ponto focal das comunicações entre os setores público e privado. }\end{array}$ \\
\hline
\end{tabular}

Tabela 2: Práticas Associadas ao Segmento de Distribuição de Combustíveis

\begin{tabular}{|c|c|}
\hline Prática & Motivo de Exclusão \\
\hline Clusters de Frete (Aldeia de Frete) & $\begin{array}{l}\text { Para o setor de distribuição de combustíveis, essa prática já existe, pois as distribuidoras ficam insta- } \\
\text { ladas próximas às refinarias de forma estratégica, para obter otimização do frete entre a empresa } \\
\text { Petrolífera e os distribuidores. Assim, a entrega do produto ocorre por meio de dutos, de forma que } \\
\text { os principais distribuidores de combustíveis acabam ficando agrupados na maioria das vezes. }\end{array}$ \\
\hline $\begin{array}{l}\text { Agendamentos para entregas nos grandes } \\
\text { polos geradores de Viagens }\end{array}$ & $\begin{array}{l}\text { Esta prática não se aplica ao segmento de distribuição de combustíveis, no que tange a sua entrega, } \\
\text { pois, no caso das distribuidoras de combustíveis, a entrega é realizada para cada cliente, sem que haja } \\
\text { aglomeração de caminhões em um mesmo local. }\end{array}$ \\
\hline $\begin{array}{l}\text { Mudança na localização dos grandes } \\
\text { geradores de viagem }\end{array}$ & $\begin{array}{l}\text { Esta prática já existe no cenário da distribuição de combustíveis, pois as refinarias de petróleo, na } \\
\text { maioria das vezes, ficam nas regiões metropolitanas, não nas capitais dos estados, onde há maior } \\
\text { aglomeração de pessoas. A construção dessas refinarias fora das capitais ocorre justamente pelo fato } \\
\text { de ser um grande polo gerador de viagem. As distribuidoras, por sua vez, ficam alojadas ao lado das } \\
\text { refinarias, facilitando o transporte por dutos e reduzindo os seus custos de transporte, ao mesmo } \\
\text { tempo em que, por estar fora dos grandes centros urbanos, consegue uma mobilidade maior para } \\
\text { poder realizar suas entregas para os clientes. }\end{array}$ \\
\hline $\begin{array}{l}\text { Taxa de estacionamento para carga e } \\
\text { descarga }\end{array}$ & $\begin{array}{l}\text { Esta prática já existe no cenário da distribuição de combustíveis, pois as refinarias de petróleo, na } \\
\text { maioria das vezes, ficam nas regiões metropolitanas, não nas capitais dos estados, onde há maior } \\
\text { aglomeração de pessoas. A construção dessas refinarias fora das capitais ocorre justamente pelo fato } \\
\text { de ser um grande polo gerador de viagem. As distribuidoras, por sua vez, ficam alojadas ao lado das } \\
\text { refinarias, facilitando o transporte por dutos e reduzindo os seus custos de transporte, ao mesmo } \\
\text { tempo em que, por estar fora dos grandes centros urbanos, consegue uma mobilidade maior para } \\
\text { poder realizar suas entregas para os clientes. }\end{array}$ \\
\hline
\end{tabular}

Assim, foram identificadas 21 práticas com potencial de implantação no segmento de distribuição de combustíveis. Foi estruturado um questionário para a avaliação destas práticas, sob a perspectiva das empresas distribuidoras de combustíveis, segundo a sua importância, dentro de uma escala Likert, com a gradação variando entre 1 (Muito Negativo) e 5 (Muito Positivo). Os questionários foram aplicados a cinco especialistas que atuam no setor de transporte das empresas distribuidoras de combustíveis entrevistados, com vasta experiência na área de estudo (20 a 38 anos) e cargos estratégicos (consultores, coordenadores e gerentes) nas organizações em que fazem parte. Os entrevistados avaliaram as práticas quanto a sua: (i) eficiência, definida por maior agilidade nas entregas e; (ii) custo, definido como o desembolso de frete pago pelas distribuidoras. Quanto maior a eficiência da prática em avaliação, maior deveria ser sua pontuação na pesquisa. Já para custos, quanto mais econômico, do ponto de vista do distribuidor de combustíveis, maior deveria ser sua pontuação.

Os dados foram analisados com a aplicação dos software SPSS (Statistical Package for the Social Sciences). A purificação da base de dados foi realizada por meio do tratamento estatístico 
denominado critério de Grubbs (Grubbs, 1969), cujo objetivo é a eliminação de resultados extremos (do inglês, outliers). Após o tratamento estatístico, o resultado obtido, segundo os critérios de eficiência e custo, para as distribuidoras, é exposto na Tabela 3.

Tabela 3: Classificação final após aplicação do método de Grubbs

\begin{tabular}{|c|c|c|c|}
\hline \multirow{2}{*}{ PRÁTICAS (HOLGUIN-VERAS) } & \multicolumn{3}{|c|}{ RESULTADO } \\
\hline & Média Eficiência & Média Custo & Média Geral \\
\hline Entrega fora do Horário Comercial (das $19 \mathrm{~h}$ às $06 \mathrm{~h}$ ) & 4,40 & 4,25 & 4,33 \\
\hline Rotas alternativas para caminhões & 4,40 & 3,60 & 4,00 \\
\hline Programa de agendamento de horários para entregas & 4,00 & 3,80 & 3,90 \\
\hline $\begin{array}{l}\text { Criar uma Parceria Público-Privado para Melhorar a Qualidade na Entrega de } \\
\text { Carga (FQP) }\end{array}$ & 4,00 & 3,80 & 3,89 \\
\hline Programas de reconhecimento & 4,60 & 3,00 & 3,80 \\
\hline Programas de certificação & 4,60 & 3,00 & 3,80 \\
\hline Sistemas de Informação em Tempo Real & 5,00 & 2,80 & 3,78 \\
\hline Redução da Poluição causada pela Marcha lenta dos Caminhões & 4,00 & 3,40 & 3,70 \\
\hline Educar Funcionários & 4,00 & 3,40 & 3,70 \\
\hline Regulamento antirruído & 4,20 & 3,20 & 3,70 \\
\hline Designar uma pessoa chave para as questões de transporte. & 4,00 & 3,40 & 3,67 \\
\hline Roteamento Dinâmico & 5,00 & 2,25 & 3,63 \\
\hline Edifícios para carga, descarga e estacionamento & 4,00 & 3,20 & 3,60 \\
\hline Criar um Comité Consultivo de Carga (FAC) & 4,00 & 3,00 & 3,56 \\
\hline Criar um Comité Consultivo Técnico (TAC) & 3,80 & 3,00 & 3,44 \\
\hline $\begin{array}{l}\text { Iniciativas mitigadoras para os impactos negativos que os operadores geram ao } \\
\text { Meio Ambiente. }\end{array}$ & 3,80 & 3,00 & 3,40 \\
\hline Programa de Mudança dos Modos de Transporte & 4,40 & 2,00 & 3,20 \\
\hline Sistemas de Detecção Vertical Altura & 3,00 & 3,00 & 3,00 \\
\hline Pedágio & 3,20 & 1,25 & 2,33 \\
\hline Restrições por tamanho do veículo e de peso & 2,40 & 2,00 & 2,20 \\
\hline Tributação & 3,00 & 1,25 & 2,13 \\
\hline
\end{tabular}

Analisando conjuntamente os critérios de eficiência e de custos (coluna Média Geral na Tabela 3), verifica-se que as práticas com melhor pontuação são entregas noturnas ( fora do horário comercial) e rotas alternativas. Dentre estas duas, a entrega noturna também destaca separadamente nos dois critérios. Desta forma, foi desenvolvido um estudo de caso em uma empresa distribuidora de combustíveis para analisar a prática de distribuição noturna sob a perspectiva da sustentabilidade econômica e ambiental, bem como o nível de serviço, da operação.

\section{ESTUDO DE CASO}

Nesta seção, são apresentadas a descrição das operações avaliadas neste estudo, as técnica de coleta de dados e os métodos de avaliação utilizados.

\subsection{Descrição das operações avaliadas neste estudo}

A restrição de circulação de veículos de carga na cidade do Rio de Janeiro é regulamentada por meio do decreto $37.784 / 2013$, que proíbe a circulação de veículos de grande porte no polígono centro, entre $06 \mathrm{~h}$ e $21 \mathrm{~h}$ nos dias úteis. As demais áreas da cidade possuem restrições apenas nos horários de pico (das $6 \mathrm{~h}$ às $11 \mathrm{~h}$ e das $17 \mathrm{~h}$ às $21 \mathrm{~h}$ ), conforme apresentado na Figura 1. 
Contudo, no mês de agosto de 2016, a prefeitura da cidade do Rio de Janeiro determinou a extensão da restrição de circulação de veículos de carga no período diurno (das $6 \mathrm{~h}$ às $21 \mathrm{~h}$ ), que anteriormente atingia apenas o polígono centro, para a zona sul da cidade, permitindo que as entregas fossem realizadas apenas de $21 \mathrm{~h}$ a $06 \mathrm{~h}$ durante o período de ocorrência dos jogos olímpicos, conforme apresentado na Figura 2. Esta decisão foi tomada visando à redução do congestionamento do trânsito, com o objetivo de facilitar o deslocamento das delegações e transporte de materiais para os jogos.

Por esse motivo, a empresa distribuidora de combustíveis realizou, durante o mês de agosto, o abastecimento de seus postos de combustíveis, localizados na Zona Sul da cidade, no período noturno. Assim, com base nestes dados, foi possível realizar uma análise comparativa dos resultados da entrega noturna em relação à entrega padrão, que é realizada durante o dia.

A distribuidora de combustíveis em estudo possui 12 clientes localizados na zona sul da cidade, sendo dois deles localizados fora da área de restrição. Entretanto, tendo em vista que suas entregas geralmente são casadas com os demais clientes localizados na área de restrição, estes também tiveram suas entregas realizadas durante o período noturno no mês de agosto de 2016. As distâncias entre os clientes e a refinaria, localizada no município em Duque de Caxias e de onde partem as rotas, variam de 42 a $46 \mathrm{~km}$.

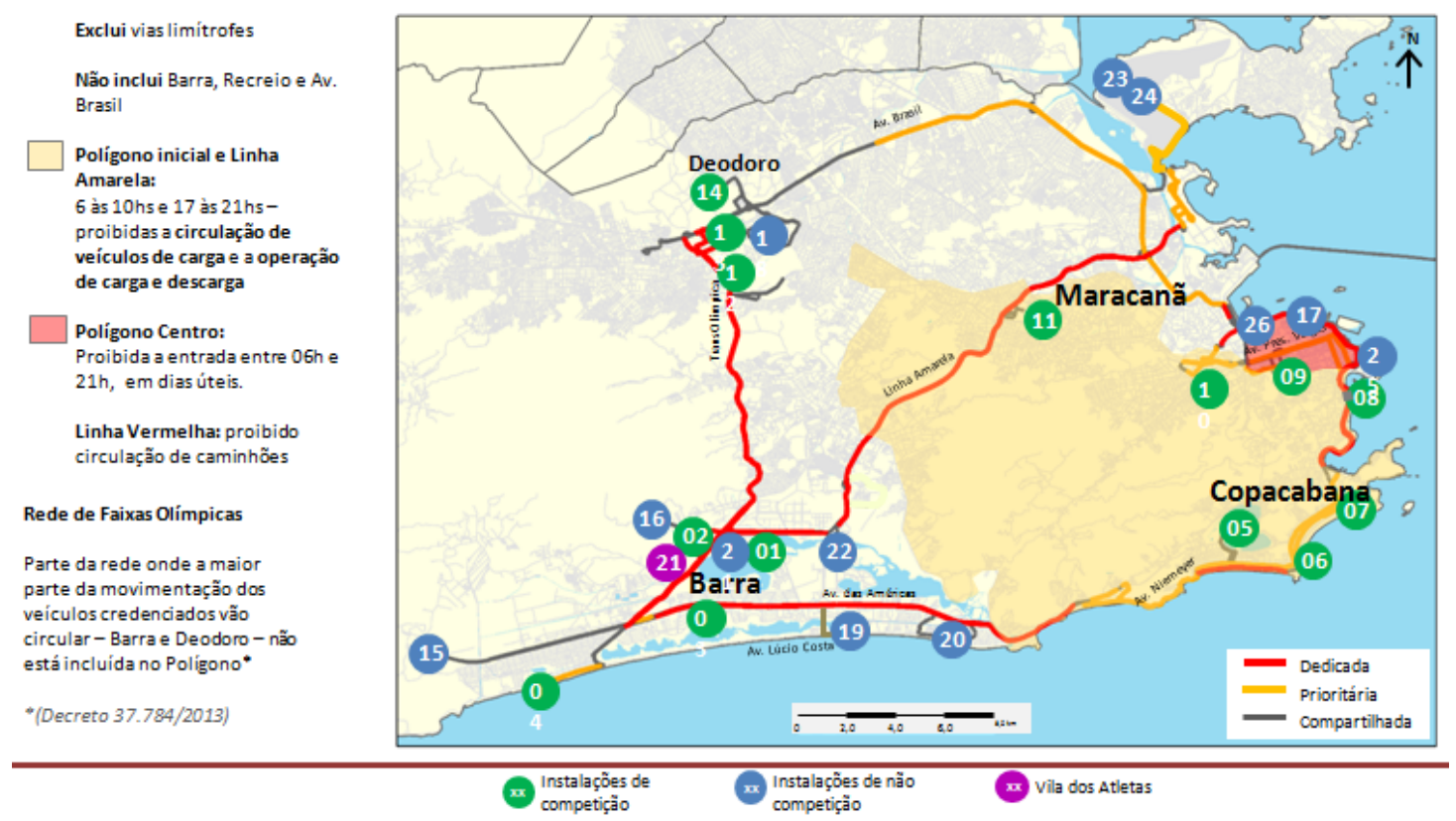

Figura 1. Polígono Original da Cidade do Rio de Janeiro (CET-Rio, 2016)

A distribuição de combustíveis é realizada por caminhões-tanque compartimentados (compartimentos de $5 \mathrm{~m}^{3}$ ), de modo que pode ser realizadas entregas a mais de um cliente na mesma viagem. A frota utilizada para a entrega, com idade entre 2009 e 2015, é composta por: caminhões truck de quatro eixos, com capacidade de transportar até $20 \mathrm{~m}^{3}$ por viagem, e composições de caminhão trator e semi-reboque (cavalo mecânico e carreta), cuja capacidade da frota varia entre $30 \mathrm{~m}^{3}$ e $35 \mathrm{~m}^{3}$. Atualmente, $17 \%$ da frota é composta por caminhões truck de $20 \mathrm{~m}^{3}$; $49 \%$ da frota é de carretas com capacidade de $30 \mathrm{~m}^{3}$; e $34 \%$ da frota corresponde a carretas com capacidade de $35 \mathrm{~m}^{3}$, utilizadas para realizar entregas de grande volumes ou para um número elevado de clientes. 


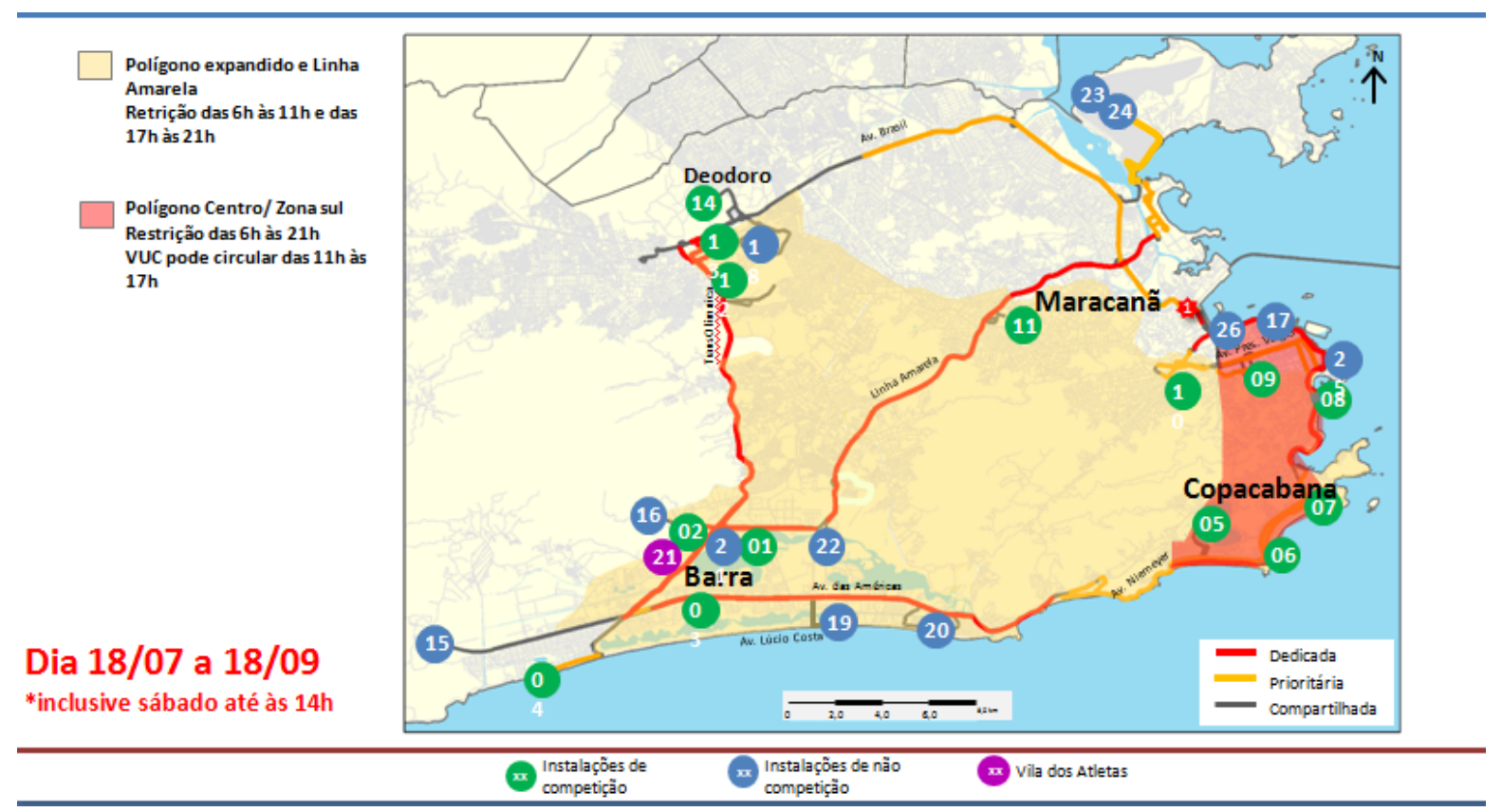

Figura 2. Polígono durante as Olimpíadas na Cidade do Rio de Janeiro (CET-Rio, 2016)

\subsection{Coleta de dados}

Foram utilizados dados referentes a todas as viagens, realizadas em junho e agosto, para abastecimento dos postos de combustível da Zona Sul da cidade do Rio de Janeiro. Os dados referentes a agosto representam a amostra de entrega noturna. Adotou-se o mês de junho como referência para a coleta de dados referentes à entrega diurna.

Os dados foram agrupados nos seguintes itens: (i) tempo - ida, volta e entrega; (ii) distância - ida, volta e entrega; (iii) velocidade média - ida, volta e entrega; (iv) número de clientes atendidos. Além disso, também foram levantados o consumo médio de combustível e o custo de mão de obra para ambos os processos de entrega.

É importante destacar que nem sempre as rotas realizadas para o mês de junho eram idênticas ao mês de agosto, havendo variações com relação ao número e aos clientes atendidos em cada viagem. Assim, caso fossem consideradas apenas as rotas idênticas para a análise comparativa entre as entregas diurnas e noturnas, o tamanho da amostra ficaria muito limitado. Ainda, o maior percurso das rotas realizadas é o deslocamento da refinaria até o primeiro cliente da Zona Sul a ser abastecido. Estas distâncias variam de 42 a $46 \mathrm{~km}$, enquanto a distância máxima entre os clientes é de $4 \mathrm{~km}$. Desta forma, optou-se por considerar os dados da rota até o primeiro cliente atendido para realizar a análise comparativa, não sendo abordados na análise os deslocamentos entre clientes envolvidos no percurso, tendo em vista a pouca influência que estes exerciam no trajeto, não computando $10 \%$ do tempo de viagem entre a base e o cluster analisado. Ainda, justifica-se esta consideração por permitir um aumento significativo do tamanho da amostra, que passou a ser composta por 73 pares de viagens de entrega noturna e diurna.

Os dados coletados foram tabulados e, em seguida, realizou-se o teste de Shapiro-Wilk para verificar a normalidade da amostra, sendo o p-valor encontrado superior a 0,05 (nível de significância adotado) para todos os dados analisados (BUSSAB e MORETTIN, 1987). Assim, podese afirmar que a amostra segue uma distribuição normal. 


\subsection{Método de avaliação}

Nesta seção, é apresentado o método de avaliação adotado para analisar o impacto da operação sob a perspectiva da sustentabilidade econômica e ambiental, bem como para a eficiência da operação.

\subsubsection{Método de avaliação da eficiência da operação}

A avaliação para comparação da eficiência de cada estratégia de distribuição (entrega noturna e diurna) baseou-se nos seguintes parâmetros: tempo de descarga nos clientes; tempos de viagem; rendimento do caminhão em km/l; a velocidade média dos veículos e o consumo total dos combustíveis durante os dois períodos analisados.

Destaca-se que as rotas realizadas, tanto para o mês de Junho quanto para o mês de Agosto, quando foram realizadas as entregas diurnas e noturnas, respectivamente, tiveram caminhos similares, o que permitiu analisar a influência direta do horário da entrega no tempo de deslocamento. Os caminhões de combustível não acessam os túneis Santa Barbara e Rebouças, dois dos principais acessos a esta região da cidade. Tal restrição obriga o motorista a trafegar pela região central da cidade do Rio de Janeiro para que o caminhão chegue às localidades de entrega. Ainda, é importante frisar que a distribuição de combustíveis é realizada por caminhões compartimentados. Por isso, em cada viagem realizada, pode ocorrer à entrega para mais de um cliente.

\subsubsection{Método de avaliação econômica}

A realização de entregas no período noturno tende a implicar em maiores gastos de remuneração total dos motoristas, devido à necessidade de pagamento do adicional noturno. Porém, entregas noturnas tendem a trazer vantagens em relação ao aumento da velocidade média e do rendimento do veículo (km/l), permitindo assim a redução de gastos com combustíveis e um possível aumento do número de viagens diárias com o mesmo veículo. Desta forma, a avaliação econômica para a comparação da distribuição em período noturno e em período diurno se baseou em três pilares: o consumo de combustível; a possibilidade do aumento de viagens diárias por veículo sem infringir a lei do motorista; e a comparação dos gastos com motoristas nos dois períodos em análise.

Nesse sentido, foi necessário identificar a ocorrência de viagens rigorosamente iguais, durante os meses estudados, de modo a verificar o tempo total de viagem por caminhão, utilizando a mesma rota, durante os períodos distintos. Além disso, para verificar a possibilidade de uma segunda viagem, foram estudadas outras entregas ocorridas na mesma data, com o mesmo número de clientes atendidos. Assim, foi possível verificar a possibilidade do aumento de viagens diárias por veículo, respeitando-se os parâmetros da lei 13.103/2015, que determina o encarregado de transitar com o veículo obedeça às oito horas de direção, podendo chegar a, no máximo, dez horas de direção diária, sendo obrigatório o pagamento das horas extraordinárias nesse caso. Para estas viagens, foi realizado então o cálculo dos gastos com motoristas, considerando o pagamento de adicional noturno; horas extras e número de motoristas envolvidos na viagem.

Para a realização do cálculo da remuneração dos motoristas, considerou-se o piso salarial de R\$1.840, 92, de acordo com dados do Sindicato de Condutores de Veículos Rodoviários e Trabalhadores em Transportes de Cargas em Geral e Passageiros no Município do Rio de Janeiro. Ainda, é importante salientar que as horas extras correspondem à remuneração de uma hora 
regular de trabalho mais cinquenta por cento deste valor. Já o pagamento de adicional noturno, corresponde a uma hora regular trabalhada, mais $20 \%$ desse valor.

\subsubsection{Método de avaliação ambiental}

A avaliação ambiental se baseia na comparação de quanto se deixa de emitir de Gases de Efeito Estufa (GEE) e de poluentes atmosféricos devido à redução do consumo de combustível que a operação de entrega noturna permite em relação à entrega diurna. Os poluentes analisados foram o $\mathrm{CO}$ (monóxido de carbono), $\mathrm{NO}_{\mathrm{x}}$ (óxido de nitrogênio), $\mathrm{NMHC}$ (hidrocarbonetos com a exceção de metano), MP (material particulado). Os GEE são $\mathrm{CO}_{2}$ (dióxido de carbono), $\mathrm{N}_{2} \mathrm{O}$ (óxido nitroso) e $\mathrm{CH}_{4}$ (metano).

Para o cálculo das emissões dos poluentes atmosféricos (PA) e GEE, foi adotado o método bottom-up, de modo que se multiplicaram os fatores de emissão de cada gás, obtidos em MMA (2013), pelo consumo médio de combustível para cada veículo de combustão interna utilizado na operação. Ressalta-se que os veículos são movidos a diesel S10 B7, mistura que contém 7\% em volume de biodiesel e 93\% em volume de óleo diesel de petróleo (MMA, 2013). Os fatores de emissão considerados no estudo são do 2을 Inventário Nacional de Emissões Atmosféricas por Veículos Automotores Rodoviários (MMA, 2013). Ainda, para estimar o impacto direto dos gases de efeito estufa, foi utilizada a conversão das emissões de CH4 e N2O para o equivalente de CO2 (cálculo do CO2 equivalente).

\section{RESULTADOS E ANÁLISES}

A Figura 3 apresenta a diferença na velocidade média operacional nas rotas para os clientes localizados na Zona Sul do Rio de Janeiro em função do horário da distribuição (entrega diurna e noturna). Observa-se que a mudança do horário das entregas do período diurno para o noturno possibilitou um aumento médio de $66 \%$ na velocidade média operacional dos veículos, que passou de $20 \mathrm{~km} / \mathrm{h}$ para $33 \mathrm{~km} / \mathrm{h}$. Destaca-se que, para entregas em alguns dos clientes estudados, o aumento da velocidade média operacional superou 75\%.

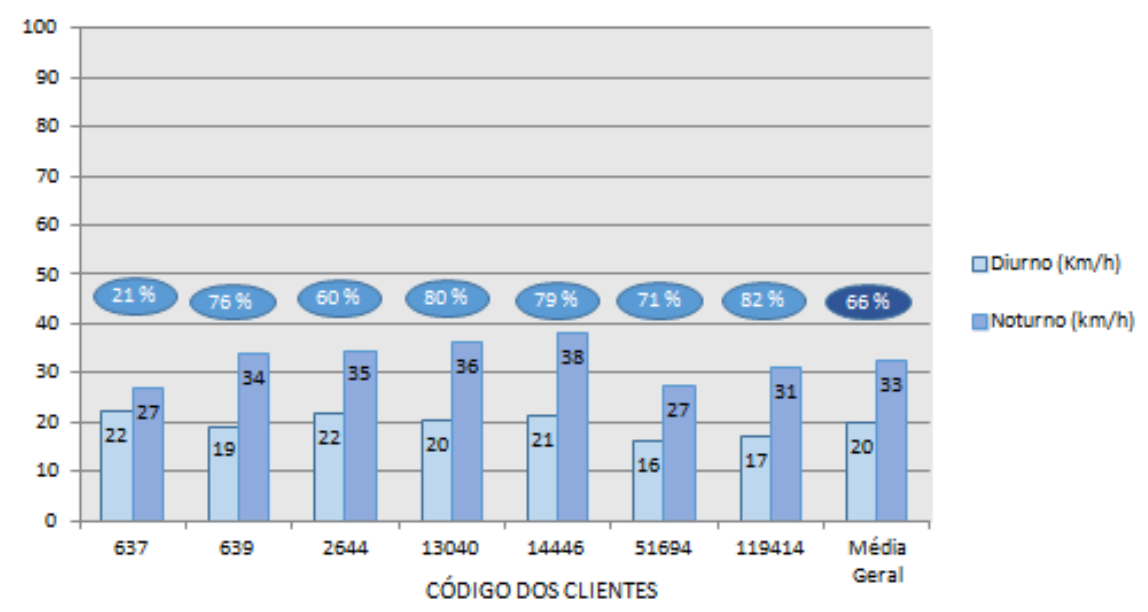

Figura 3. Velocidade Média $(\mathrm{km} / \mathrm{h})$

O aumento da velocidade média operacional obtida por meio da mudança das entregas do período diurno para o noturno possibilitou o aumento no rendimento energético (km/l) para os três tipos de veículo em função do horário da distribuição (entrega diurna e noturna), con- 
forme apresentado na Figura 4. Verifica-se que, para os três tipos de caminhão, houve um incremento do rendimento energético dos veículos: $11 \%$ para o veículo de $20 \mathrm{~m}^{3}, 16 \%$ para os veículos de $30 \mathrm{~m}^{3}$ e $17 \%$ para os veículos de $35 \mathrm{~m}^{3}$.

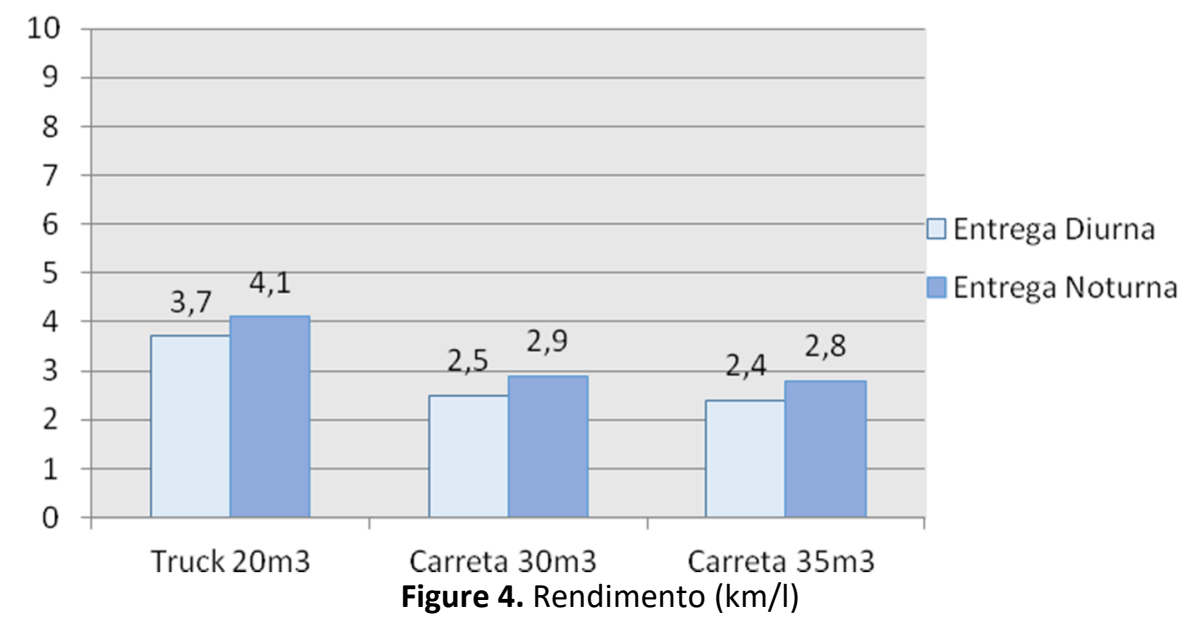

Outros aspectos analisados para avaliar a variação na eficiência da operação em função do horário de distribuição são: tempo de descarga e tempo de viagem. Observou-se um incremento de 7\% no tempo médio de descarga durante o mês de agosto (noturno) (de 46'15" para 49' 42"). Por meio do teste $t$-student, foi verificado que esta diferença não é significativa estatisticamente. Entretanto, esta variação pode ser explicada devido à falta de mão de obra especializada para realizar a descarga no período noturno. Durante o período diurno, a descarga é realizada por funcionários treinados. Contudo, no período da noite, ocorreu a troca de turno e os funcionários escalados para esse horário não possuem treinamento para realizar o processo de descarga.

A Figura 5 apresenta as variações nos tempos médios de viagem até a entrega do produto em cada cliente nos meses de Junho e Agosto. Observa-se uma redução de 34\% no tempo médio de viagem durante o período noturno, com alguns clientes alcançando patamares superiores à $40 \%$ na redução do tempo de viagem. Para estes dados, foi realizado o teste $t$-student, que comprovou que as diferenças nos tempo de viagem durante o período noturno é estatisticamente significativa. Assim, conclui-se que o tempo de viagem durante o período noturno é consideravelmente menor, quando comparado ao período diurno.

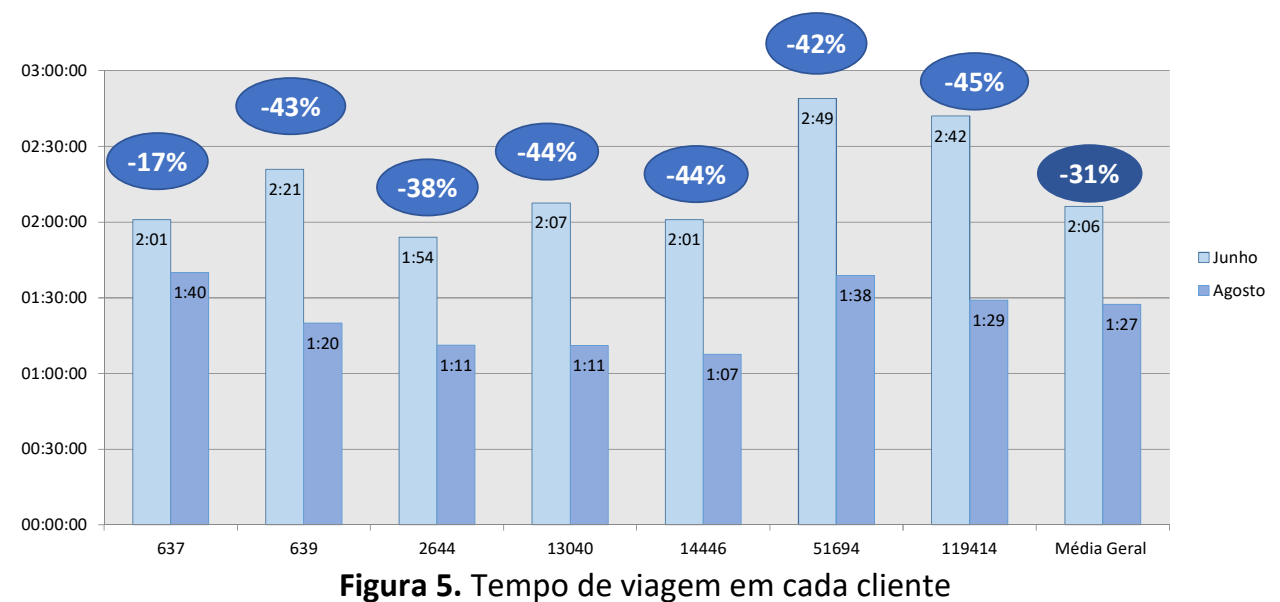

Após identificar os benefícios sob o ponto de vista da eficiência, avaliou-se a oportunidade 
de transformar as economias de tempo e o aumento do rendimento do veículo em ganhos para os operadores de frete. Uma vantagem direta do acréscimo do rendimento energético dos veículos, obtida por meio da entrega noturna (Figura 4), foi uma economia de $9 \%$ do total de combustível consumido entre os meses de Junho (diurno) e de Agosto (noturno), o que sugere uma redução com o gasto com consumo de combustível.

Ainda, devido ao menor tempo de deslocamento nas viagens ocorridas no período noturno, pode-se avaliar se essa redução possibilitaria um aumento do número de viagens diárias por caminhão. Conforme detalhado na seção 3.2.2, buscou-se levantar a viagens com rotas rigorosamente iguais (incluindo as entregas de todos os clientes) nos dois períodos em análise. Neste caso, foram identificadas três rotas idênticas. Em seguida, foram verificadas outras entregas ocorridas na mesma data, com o mesmo número de clientes atendidos, para que não houvesse distorção nos tempos estudados. 0 objetivo é analisar a possibilidade de o mesmo veículo realizar uma segunda viagem no mesmo dia, tanto para o período noturno quanto para o período noturno, respeitando-se os parâmetros da lei 13.103/2015. Dessa forma, foram realizadas três análises comparativas, como exposto na Figura 6, que apresenta o tempo de cada viagem, o tempo total de viagem do caminhão por dia, bem como o limite máximo de horas de trabalho permitido pela lei 13.103/2015 (no máximo, dez horas de direção diária, sendo obrigatório o pagamento das horas extraordinárias nesse caso).

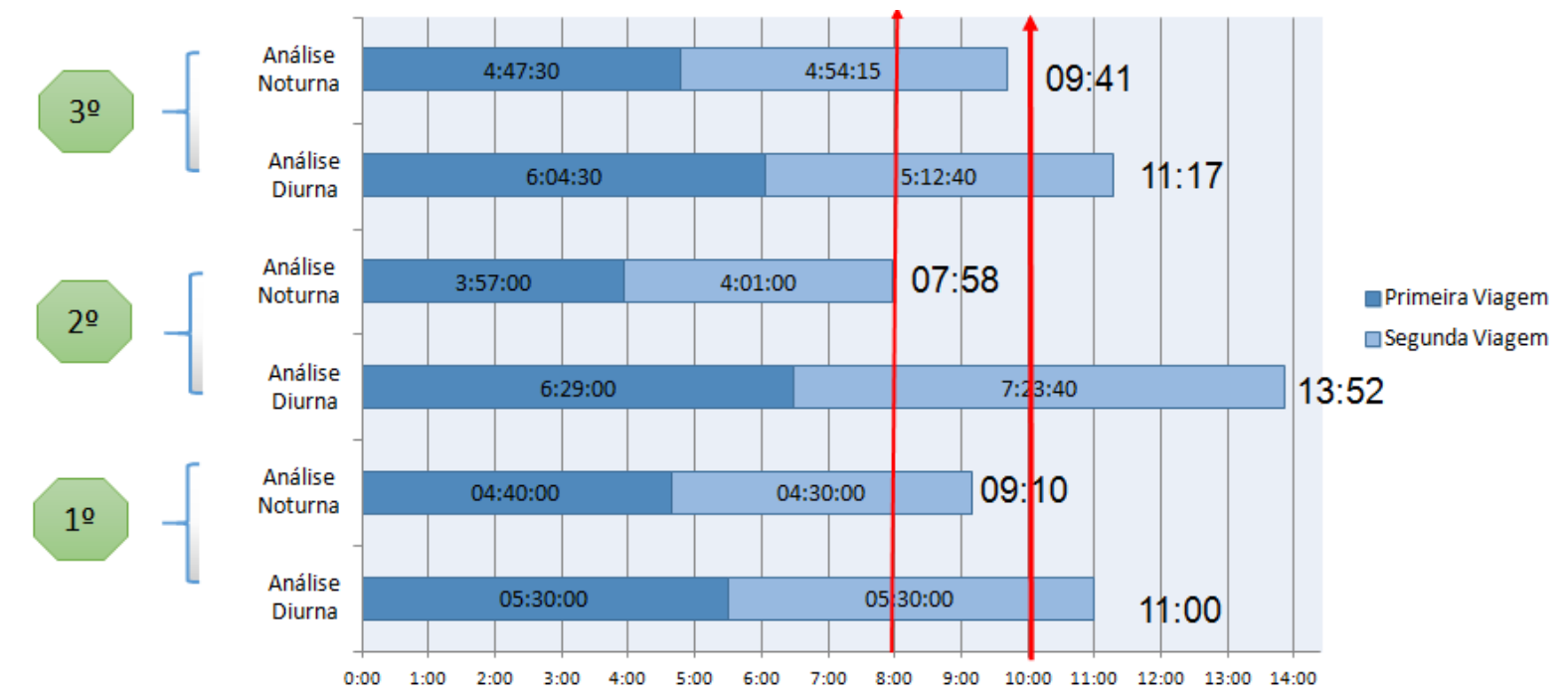

Figure 6. Análise de duas viagens diárias por veículo

Nos três casos analisados, os tempos de viagem para a entrega noturna ficaram abaixo das dez horas máximas de trabalho permitidas por lei, enquanto nenhuma das três análises diurnas permitiu a realização das duas viagens sem infringir a lei 13.103/2015. Constatou-se, assim, que a redução de tempo obtida pela entrega em horário noturno possibilita que duas ou mais viagens sejam feitas por um mesmo caminhão por dia, permitindo assim uma redução da frota disponibilizada para a distribuidora e, consequentemente, a redução dos custos de frete, já que esses caminhões são contratados para ficarem exclusivos a serviço da distribuidora.

No entanto, é importante ressaltar que, apesar do estudo apontar a possibilidade de aumento do número de entregas diárias por caminhão, as entregas realizadas durante o período noturno suscitam o pagamento de adicional noturno aos empregados que estejam trabalhando nesse turno. Desta forma, foi necessário avaliar o impacto da mudança do horário de entrega no valor 
gasto com a mão de obra do motorista do caminhão, um dos principais componentes do custo de frete, considerando o gasto com adicional noturno, horas extras e o número de motoristas envolvidos na viagem. A Tabela 4 apresenta os resultados do cálculo do custo com motorista para cada uma das análises, comparando os valores para entregas noturnas e diurnas.

Tabela 4: Análises do Custo do Motorista (Diurno X Noturno)

\begin{tabular}{|c|c|c|c|c|c|c|}
\hline \multirow{2}{*}{ Variáveis } & \multicolumn{2}{|l|}{$1^{\circ}$ Análise } & \multicolumn{2}{|l|}{$2^{\circ}$ Análise } & \multicolumn{2}{|l|}{$3^{\circ}$ Análise } \\
\hline & Diurno & Noturno & Diurno & Noturno & Diurno & Noturno \\
\hline Quant./Motorista & 2 & 1 & 2 & 1 & 2 & 1 \\
\hline Salário do motorista & $\mathrm{R} \$ 1.840,35$ & - & $\mathrm{R} \$ 1.840,35$ & - & $\mathrm{R} \$ 1.840,35$ & - \\
\hline $\begin{array}{l}\text { Salário do motorista com adicional } \\
\text { noturno }(20 \%)\end{array}$ & - & $\mathrm{R} \$ 2.208,42$ & - & $\mathrm{R} \$ 2.208,42$ & - & $R \$ 2.208,42$ \\
\hline Valor mensal da hora extra noturna & - & $\mathrm{R} \$ 331,26$ & - & - & - & $\mathrm{R} \$ 331,26$ \\
\hline CUSTO TOTAL DOS MOTORISTAS & $\mathrm{R} \$ \mathbf{3 . 6 8 0 , 7 0}$ & R\$ 2.594,89 & $\mathrm{R} \$ 3.680,70$ & $\mathrm{R} \$ \mathbf{2 . 2 0 8 , 4 2}$ & $\mathrm{R} \$ 3.680,70$ & $R \$ 2.766,05$ \\
\hline
\end{tabular}

Observa-se, a partir da Tabela 4, que, para os três casos avaliados, a opção de entrega envolvendo apenas um motorista durante o horário noturno foi a de menor custo, mesmo existindo a necessidade de pagamento de horas extras e adicional noturno. Para o período diurno, a impossibilidade de utilizar apenas um motorista para duas viagens diárias afetou diretamente o desembolso com esses empregados, sendo obrigatório o uso de dois motoristas.
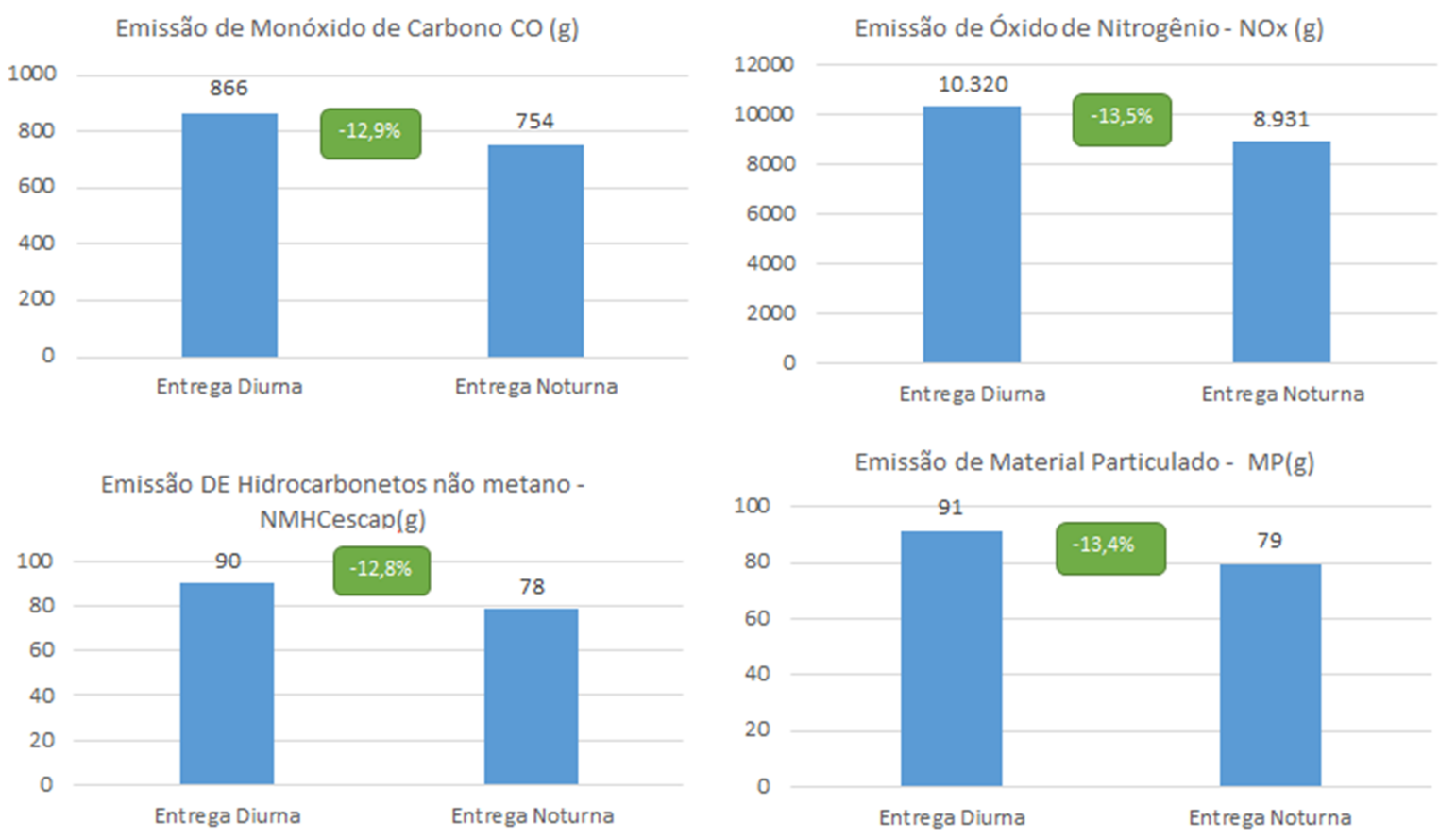

Figura 7. Emissão de poluentes atmosféricos

Ainda, com relação à avaliação ambiental, foi possível quantificar os ganhos ambientais gerados a partir da redução do consumo de combustível atingida pela realização de entregas no período noturno. A Figura 7 apresenta a comparação entre as emissões de gases poluentes produzidos durante os dois períodos em análise: monóxido de Carbono; óxido de nitrogênio; hidrocarbonetos não metano; e material particulado. Nota-se que, em média, houve redução de $13 \%$ na emissão dos gases poluentes durante o período noturno, quando comparado ao período 
diurno. A mesma comparação foi realizada com relação à emissão de gás carbônico equivalente. Conforme apresentado na Figura 8, a redução obtida com a entrega noturna também foi em torno dos $13 \%$.

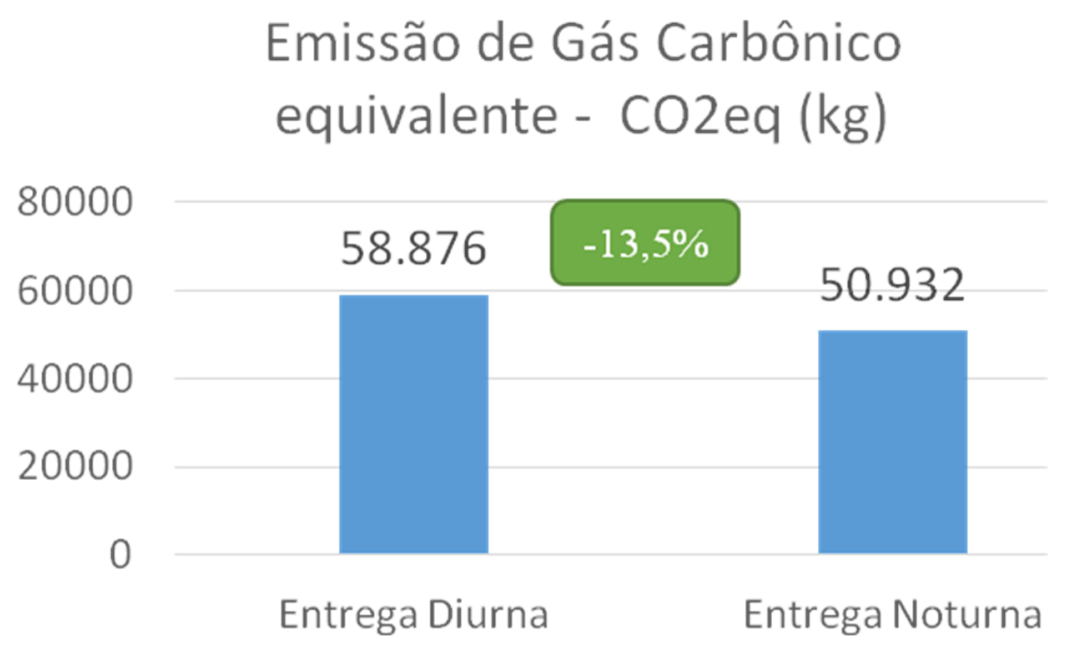

Figura 8. Emissão de Gás Carbônico equivalente - CO2eq (kg)

Ainda, com intuito de verificar o impacto com relação à poluição sonora, ponto crítico para a entrega noturna, foi realizado contato com os doze postos de combustíveis da Zona Sul do Rio para identificar se houve reclamações por parte de vizinhos com relação à emissão de ruídos. Entretanto, não foi levantada nenhuma reclamação durante o período de entregas noturnas.

Enfim, os resultados apresentados nesta seção ratificam os benefícios que as entregas noturnas, no contexto da distribuição de combustíveis, podem trazer não só para os operadores, mas também para toda a sociedade inserida no contexto urbano.

\section{CONCLUSÕES}

O objetivo deste estudo consistiu em avaliar aspectos relacionados à eficiência das entregas de combustíveis na zona do Sul da cidade do Rio de Janeiro, bem como os aspectos que tangem a sustentabilidade econômica e ambiental desta operação.

Com relação ao tempo total das viagens entre a base e os clientes localizados na zona sul da cidade do Rio de Janeiro, observou-se uma redução no tempo de viagem de 34\% no período noturno. Além disso, houve aumento no rendimento dos caminhões de até $17 \%$, dependendo do veículo utilizado. Também foi identificado um aumento médio de $66 \%$ na velocidade média dos veículos durante a viagem entre a base, localizada em Duque de Caxias-RJ e os clientes localizados na zona sul da cidade do Rio de Janeiro. Estes resultados favorecem a troca de turno para o período noturno, ocasionados pela maior agilidade nas entregas.

Em posse dos resultados obtidos para a avaliação da eficiência durante os períodos estudados, foi possível mensurar os benefícios, em termos econômicos, que a redução nos tempos de viagem durante o período noturno pode trazer para operação. Logo, avaliou-se a possibilidade da realização de duas viagens por um mesmo caminhão no dia, ficando comprovado, nos três casos estudados, que o período noturno permite que ocorra esta conjuntura, enquanto que, em nenhum dos testes realizados para a entrega diurna, isto foi possível, respeitando-se a lei $13.103 / 2015$. Nos três casos apurados, o custo do motorista no período noturno foi mais van- 
tajoso que os custos gerados pelo período diurno, mesmo com o pagamento de adicional noturno e hora-extra.

Outro ponto a ser destacado sobre a viabilidade econômica das entregas noturnas é a redução do consumo de combustível da frota, quando comparado às entregas diurnas. A redução no tempo de percurso, ocasionada pela redução nos congestionamentos trouxe o aumento do rendimento do veículo. Estes aspectos levaram a uma redução, na ordem de 9\%, dos gastos com consumo de combustível na frota utilizada para atender a área de estudo, o que impulsionou uma redução média de $13 \%$ da emissão de gases poluentes e GEE. Este resultado ratifica os benefícios que a prática de entregas noturnas pode trazer ao meio ambiente. Contudo, é importante salientar que, no presente estudo, não foi analisado o impacto da entrega noturna em relação à poluição sonora, ponto crítico para esta medida, sendo observado apenas que não houve reclamações, por parte de vizinhos, com relação às entregas noturnas.

Enfim, a prática de entregas em horário noturno configura-se como uma possível opção de melhoria para o transporte de cargas, não só para os agentes logísticos, mas também para a comunidade e para o gestor público. A mudança nos horários de circulação dos caminhões reduziria o trânsito de veículos pesados nos horários de maior movimentação da comunidade pelas ruas das grandes cidades, além de reduzir os gases poluentes emitidos no meio ambiente.

\section{REFERÊNCIAS}

Alessandri, A.; A. Di Febbraro; A. Ferrara e E. Punta (1998) Optimal Control of Freeways via Speed Signalling and Ramp Metering. Control Engineering Practice, v. 6, n. 6, p. 771-780. DOI: 10.1016/S0967-0661(98)00083-5.

ABNT - Associação Brasileira de Normas Técnicas (2014) ABNT Catálogo. Rio de Janeiro. Disponível em: https://www.abntcatalogo.com.br/norma.aspx?ID=325473 (Capturado em 17 de setembro de 2016)

ANTT - Agência Nacional de Transportes Terrestres (2004) Resolução no 420, de 12 de fevereiro de 2004. Aprova as Instruções Complementares ao Regulamento do Transporte Terrestre de Produtos Perigosos. Rio de Janeiro. Disponível em: http://www.antt.gov.br/index.php/content/view/1420/Resolucao_n_420.html

Arvindsson, N. (2013) The milk run revisited: A load factor paradox with economic and environmental implications for urban freight transport. Transportation Research Part A, v. 51, p. 56-62. Doi:10.1016/j.tra.2013.04.001.

BESTUFS - Best Urban Freight Solutions (s/d). Disponível em: http://www.bestufs.net/bestufs1.html (Capturada em 03 de dezembro de 2017)

BR Distribuidora (2016) Ficha de Informação de Segurança de Produto Químico - FISPQ. Petrobras Distribuidora S.A. Disponível em: http://www.br.com.br/wcm/connect/9a86f549-e60c-456b-9b23-890ed437736e/fispq-comb-quero-avi-qav-jeta1.pdf?MOD=AJPERES\&CVID=lVePaID (Capturada em 18 de setembro de 2016)

Brasil (2015) Lei 13.103, de 02 de março de 2015. Dispõe sobre o exercício da profissão de motorista; altera a Consolidação das Leis do Trabalho - CLT, aprovada pelo Decreto-Lei no 5.452, de 1 o de maio de 1943, e as Leis nos 9.503, de 23 de setembro de 1997 - Código de Trânsito Brasileiro, e 11.442, de 5 de janeiro de 2007 (empresas e transportadores autônomos de carga), para disciplinar a jornada de trabalho e o tempo de direção do motorista profissional; altera a Lei no 7.408, de 25 de novembro de 1985; revoga dispositivos da Lei no 12.619, de 30 de abril de 2012; e dá outras providências. Dário Oficial da União 03 mar 2015, Seção X. Disponível em http://www.planalto.gov.br/ccivil 03/ ato2015-2018/2015/lei/l13103.htm

Bussab, W. O. e P. A. Morettin, (1987) Estatística Básica - 4를 Ed, Atual Editora.

Carvalho, C. H. R. de. (2016) Desafios da Mobilidade Urbana no Brasil. IPEA. Brasília.

Grubbs, F. E. (1969). Procedures for Detecting Outlying Observations in Samples. Technometrics, v. 11, .n. 1, p. 1-21. Disponível em: http://www.jstor.org/stable/1266761 (Capturado em 17 de julho de 2016)

Holguín-Veras, J. (2015) Improving Freight System Performance in Metropolitan Area. Transforming Transportation. Disponível em: http://pt.slideshare.net/EMBARQNetwork/improving-freight-system performance-in-metropolitan-areas-jos-holgun-vref-center-of-excellence-for-sustainable-urban-freight-systems-transforming-transportation-2015 (Capturado em 20 de março de 2016)

IBGE - Instituto Brasileiro de Geografia e Estatística (2010) CENSO 2010. Rio de Janeiro. Disponível em www.censo2010.ibge.gov.br (Acesso em Maio de 2016)

Mckinnon, A.; S. Cullinane e M. Browne et al (2010) Green logistics: improving the environmental sustainability of logistics. v.1 Londres, Philadelfia, Nova Delhi, Kogan Page.

MMA - Ministério do Meio Ambiente (2016) Projeto BRA 05/043 - Concepção e Capacitação em Metodologia para Elaboração de Planos de Ação de Emergência a Serem Utilizados por Órgãos Públicos Federais, Estaduais e Municipais, Capazes de Proporcionar Respostas Organizadas e Rápidas aos Acidentes com Produtos Químicos Perigosos. Brasília. Disponível em: http://www.mma.gov.br/estruturas/sqa p2r2 1/ arquivos/relatrio do produto 3 vol i rev02 pae federal final_106.pdf (Capturado em 07/03/2016) 
NTC (s/d) ZMRC - Zona de Máxima Restrição de Circulação de Caminhões. Associação Nacional de Transporte de Carga e Logística. Disponível em: http://www.ntctec.org.br/download/arquivo/cidades-com-restricoes1.pdf (Capturado em 07/03/2016]

NTC (s/d) Restrição ao Trânsito de Veículos Automotores Pesados, do tipo caminhão. Associação Nacional do Transporte de Cargas e Logística. Disponível em http://www.ntctec.org.br/canais/downloads/tecnico-economico/?\&p=10 (Capturado em 07/03/2016)

Oliveira, C. M.; R. A. M. Bandeira; G. V. Goes; D. N. S. Gonçalves e M. A. D’Agosto (2017). Sustainable Vehicles-Based Alternatives in Last Mile Distribution of Urban Freight Transport: A Systematic Literature Review. Sustainability v. 9, p. 1324. DOI:10.3390/su9081324

Oliveira, L. K. (2013) Uma revisão sistemática da literatura científica em logística urbana no Brasil. Anais do XXVIII ANPET, Curitiba.

ONU - Organização das Nações Unidas (2016) Dois terços da população mundial devem viver em cidades até 2030. Disponível em: http://www.unmultimedia.org/radio/portuguese/2016/05/dois-tercos-da-populacao-mundial-devem-viver-emcidades-ate-2030/\#.Wh vZEqnHIV/ (Acesso em 08/11/2017)

Rio de Janeiro (2013) Decreto nº 37784 de 10 de outubro de 2013. Dispõe sobre horário de circulação de veículos de carga e operação de carga e descarga na forma que menciona, e dá outras providências. Disponível em: http://smaonline.rio.ri.gov.br/legis consulta/45194Dec\%2037784 2013.pdf (Capturado em 02/03/2016) 